\title{
Optimal Investment Timing and Size of a Logistics Park: A Real Options Perspective
}

\author{
Dezhi Zhang, ${ }^{1,2}$ Jiehui Jiang, ${ }^{1}$ Shuangyan Li, ${ }^{3}$ Xiamiao Li, ${ }^{1}$ and Qingwen Zhan ${ }^{1}$ \\ ${ }^{1}$ School of Traffic \& Transportation Engineering, Central South University, Changsha, Hunan 410075, China \\ ${ }^{2}$ Key Laboratory of Traffic Safety on Track of Ministry of Education, Central South University, Changsha, Hunan 410075, China \\ ${ }^{3}$ College of Transportation and Logistics, Central South University of Forestry and Technology, Changsha, Hunan 410004, China
}

Correspondence should be addressed to Shuangyan Li; lishuangyan585@163.com

Received 2 July 2017; Accepted 7 November 2017; Published 5 December 2017

Academic Editor: Eulalia Martínez

Copyright (C) 2017 Dezhi Zhang et al. This is an open access article distributed under the Creative Commons Attribution License, which permits unrestricted use, distribution, and reproduction in any medium, provided the original work is properly cited.

\begin{abstract}
This paper uses a real options approach to address optimal timing and size of a logistics park investment with logistics demand volatility. Two important problems are examined: when should an investment be introduced, and what size should it be? A real option model is proposed to explicitly incorporate the effect of government subsidies on logistics park investment. Logistic demand that triggers the threshold for investment in a logistics park project is explored analytically. Comparative static analyses of logistics park investment are also carried out. Our analytical results show that (1) investors will select smaller sized logistics parks and prepone the investment if government subsidies are considered; (2) the real option will postpone the optimal investment timing of logistics parks compared with net present value approach; and (3) logistic demands can significantly affect the optimal investment size and timing of logistics park investment.
\end{abstract}

\section{Introduction}

Various logistics centers have recently been established for quickly distributing freight [1]. However, this raises many important issues, such as traffic congestion, air pollution, and high energy consumption. It has been shown that freight transportation contributes to about $5.5 \%$ of global greenhouse gas emissions [2]. To respond to these issues efficiently, it has been proposed to combine multiple distribution centers and logistic operators into a logistics park. A logistics park, also known as a "logistics village" in Germany, "distribution park" in Japan, and "logistics platform" in Spain, is a particularly important component of a city logistics network [3]. In general, a city logistics network is composed of different types of logistics nodes (e.g., distribution centres and logistics parks) and logistics links. A distribution center is a logistics node mainly for end customers to provide distribution services, which remains as the following several characteristics, that is, small service radiation range and multispecies, small batch, multibatch, and short cycle, while a logistics park is a comprehensive logistics node with large size, which is commonly located in a strategic area that can easily be accessed from main highways, railways, and airports. Moreover, a logistics park typically has a large space for ample trucks, mass warehousing, office parking, and logistics services such as information transaction, distribution processing, multimodal function, and support service functions. It is also a hub for different transportation modes and local and long-distance traffic $[4,5]$.

Logistics parks have led to significant environmental effects (e.g., reducing $\mathrm{CO}_{2}$ emissions and air pollution) in Germany [6]. Owing to successful logistics park operations in Germany and Japan, there is a growing trend to introduce logistics parks in other developing countries. In China, for example, the number of logistics park projects has continued to increase, from 207 in 2006 to 457 in 2008, 754 in 2012, and 1210 in 2015 according to the fifth survey report conducted by the China Federation of Logistics \& Purchasing [7]. However, there are some important problems in the planning and operation of logistics park projects in China. China's logistics park planning and construction has great blindness due to the lack of systematic theoretical and scientific planning means and assessment. There are many factors that affect the development of logistics parks. An important factor is how to 
determine the size of logistics park [8]. Moreover, the design of logistics parks has seldom considered the uncertainty of logistic demands and logistic users' behavioral responses to project investment, leading to a lower usage rate of logistics parks. Investment in logistics parks also involves a high level of risk because of the length of the construction period and the volatility of logistic demands. Hence, the timing and size of logistics parks should be carefully considered.

There are a number of related studies on logistics parks design and investment.

A logistics park is an important logistics facility and can have a significant impact on the corresponding city logistics network. Therefore, the location of logistics parks should be integrated into the entire city logistics network design. Taniguchi et al. [11] proposed a bilevel model to determine the optimal size and location of public logistics terminals and solved the model using queuing theory and nonlinear programming techniques. Nguyen et al. [12] noted that logistics efficiency and cost were related not only to the structure of supply chains but also to the logistics network design and logistics infrastructure. Soysal et al. [13] presented a network model of wagonload traffic that aimed to determine hub location and size considering the total cost and efficiency of the network system. Vieira et al. [14] investigated a hub location problem from the perspective of network design while also considering the transportation cost and travel time and proposed a mixed integer programming formulation. Tang et al. [15] presented an optimization model for the location planning problem of logistics parks with variable capacity. Their model sought to determine optimal locations and allocate customers to the logistics parks using a hybrid heuristic algorithm. Chen et al. [16] addressed the facility layout problem in nonrectangular logistics parks with split lines, proposing corresponding mathematical programming models to obtain competitive solutions for the facility layout problem in a logistics park, solving the optimal model with an adaptive genetic algorithm with scatter search.

A logistics park is an important provider of logistic activities, linking long-haul transportation in different regions of a distributed city [17]. This facility plays an important role in promoting regional economic development, enhancing the level of logistics services, improving intensive land use, relieving pressure from roads and the environment, and increasing employment opportunities. Zacharias and Zhang [18] addressed a two-tiered freight distribution system in a big city, presenting a location-routing model to determine the optimal locations of logistics facilities (primary facilities and secondary facilities) and optimal sizes and routes for different vehicle fleets. Rivera et al. [8] considered the logistics agglomeration arising from logistics parks based on data from a survey conducted in the Zaragoza (Spain) Logistics Cluster and using structural equation modeling, demonstrating that further agglomeration into a logistics park positively impacts collaboration, specifically transportation capacity sharing.

In recent years, green logistics network design has attracted the attention of more practitioners and researchers, given that freight transportation is a major contributor to climate change and various pollution emissions. Green logistics network design focuses on improving logistics service efficiency, decreasing corresponding logistics costs, and reducing externalities while achieving a sustainable balance between economic, environmental, and social objectives (McKinnon et al. [19]. Sadjadi et al. [20] addressed a multicommodity, capacitated intermodal freight transportation network planning problem, which considered greenhouse gas emissions as the primary objective. Rudi et al. [21] assessed the effect of the traditional cost optimization approach to strategic modeling on overall logistics costs and $\mathrm{CO}_{2}$ emissions by considering the supply chain structure and different freight vehicle utilization ratios. Rao et al. [22] addressed the selected sustainable location of city logistic centers and proposed a fuzzy, multiattribute group decisionmaking technique based on a linguistic 2-tuple. Zhang et al. [3] proposed a model to address the design problem of a city logistics network; they considered the interaction between logistics authority and users, as well as the effect of economy size and taxes for $\mathrm{CO}_{2}$ emissions. Their results showed that the optimal location and size of logistics parks depend on the realized logistic demand and the size of the economy.

The aforementioned studies on design issues of logistics parks mainly focused on a static and deterministic problem. However, the regional economy, industrial structure, population size, and regional trading pattern will keep changing in the future, leading to logistics demand uncertainty that dynamically fluctuates over time. This is particularly true for some of the fastest-growing cities and the corresponding city logistics service demand pattern. It is therefore necessary to incorporate the dynamics and uncertainty of logistics demand over time into city logistics network design models.

Previous studies tended to use the net present value (NPV) approach. However, the traditional NPV approach does not consider the change of project value in investment; this approach also ignores the impact of postponement, abandonment, or expansion of an investment opportunity on project value in an irreversible and uncertain investment environment [23]. The real option ( $\mathrm{RO})$ valuation approach considers the opportunity during an investment period that goes unrecognized in NPV analysis [24]. There is a compelling need to account for time-dependent uncertainty within network designs and project investment due to their irreversible characteristics $[25,26]$. Li et al. [10] proposed a RO model to address investment and selection in transit technology given a volatile city population by considering the spatial use equilibrium of a city. Chow et al. [27] investigated the management of a transportation network in an uncertain market, applying the $\mathrm{RO}$ approach and dynamic programming to obtain the value of flexibility and to defer and redesign a network. Chow and Regan [28] proposed two models that incorporate RO into network modeling: the first is the network option design problem, which maximizes the expanded NPV of a network investment; the second model decomposes the deferral option of a network investment into individual, interacting links, or project investments. Xiao et al. [29] studied the airport capacity choice problem using a real option model. They point out that if demand uncertainty is low and capacity and reserve costs are relatively high, an airport will not acquire a real option for expansion. Gao and Driouchi [30] examined rail transit infrastructure 
investment by treating population scale and the attitudes of decision-makers or social planners as sources of risk and ambiguity. They developed an alpha-max-min multiplepriors expected utility framework to solve for the option value of rail transit investment under knighting uncertainty. Li et al. [31] proposed a real options approach for valuing the investment of a new technology for producing cellulosic biofuels based on construction lead times and uncertain fuel prices. Chow and Sayarshad [32] investigated the reference policies for nonmyopic sequential network design and timing problems, proposing a scalable reference policy value defined from theoretically consistent real option values based on sampled sequences that are estimated using extreme value distributions. Cortazar et al. [33] presented a model to determine the optimal timing for a firm to invest in environmental technologies and analyzed the key parameters affecting the optimal decisions. Bockman et al. [34] considered investment timing and optimal capacity choice for small hydropower projects using a real options-based method with continuous scaling; they found a unique price limit for initiating the project. Boomsma et al. [35] adopted a real options approach to analyze investment timing and capacity choice for renewable energy projects under different support schemes, aiming to examine investment behavior under the most extensively employed support schemes, namely, feedin tariffs and renewable energy certificate trading. Welling [36] investigated the size and timing of a renewable electricity investment, analyzing the effects of governmental support on the optimal capacity of a renewable electricity generating system. $\mathrm{Li}$ and Cai [37] applied a real option model to address the impacts of government incentives on the private investment behaviors with uncertain demand, including the choices of investment timing, capacity, and price.

To the best of our knowledge, existing studies that integrate the economic scales of logistics parks construction and operator and government subsidies based on a real option method are still scarce. This study aims to address the above knowledge gap by attaining two objectives. The first objective is to prove conjectures on determining the optimal investment timing and size of a logistics park project simultaneously under logistics demand uncertainty. The second objective is to address the impacts of government subsidies on the logistics parks investment timing and size.

The main contributions of this paper are as follows.

First, a real option model is proposed that incorporates economics of scale on logistics park projects and government investment subsidies to determine the optimal investment timing and size simultaneously. The model captures the effect of logistic demand volatility and economies of scale of a logistics park on investment timing and size decisions. Second, the thresholds of logistics demand that trigger investments in a logistics park with different sizes are explored. Third, we conduct comparative statistical analyses of investments in a logistics park. Sensitivity analyses are also conducted to assess the effect of key model parameters, such as logistics volatility, duration of construction, and discount rate. We also estimate loss in project value as a result of the adoption of the NPV method instead of the RO.
The rest of the paper is organized as follows. Section 2 presents the formulation of the model and the solution algorithm. Section 3 presents two numerical examples of the application of the model. Section 4 concludes the paper.

\section{Model Formulation}

2.1. Cost of a Logistics Park Project. Economies of scale in the construction of logistics parks refers to the phenomenon wherein the average construction cost per unit area of a logistics park decreases as the size of the logistics park increases [38-41]. Economies of scale in the operation of logistics parks refer to the phenomenon wherein the average operating cost per unit of shipment decreases as the size of the logistics park increases because of clustering and synergetic effects among logistics service providers [42, 43]. These effects should be considered in the design of logistics parks, particularly in an era of (capital and land) resource shortages and climate change.

Two kinds of costs are involved in the construction and operation of a logistics park (i.e., annual construction and annual operation costs). Both factors include economies of scale. We denote the average annual construction cost and operator cost as $C_{L}$ and $C_{0}$, respectively. They are described in detail as follows:

$$
C_{L}=\lambda M^{\rho},
$$

where $\lambda$ is the unit construction cost and $\rho$ captures the effects of the economies of scale for a logistics park.

The annual average operation cost of a logistics park is expressed in the following:

$$
C_{0}=\omega M^{\rho},
$$

where $\omega$ is the variable operator cost relevant to the corresponding size of logistics park $M$.

2.2. Joint Optimal Timing and Size Problem of a Logistics Park. Regarding the logistics park as a firm, the logistic demand is equivalent to the product and the service charge is the product price; therefore, the service charge for unit transfer should be proportional to logistics demand in service and inversely proportional to the size of the logistics park. According to logistics service demand function, we can use the following logistics service supply function to capture the above relationships.

$$
\xi(t)=q(t)-\gamma M,
$$

where $q(t)$ is the external logistics service demand of the market, $M$ is the size of the logistics park that the firm intends to build, and $\gamma$ is a nonnegative constant that indicates the slope of the liner demand function and is used for the sensitivity of the service charge to the size of logistics park. As seen in (3), the size of the logistics park is inversely proportional to the service charge for unit transfer, and the function form of this assumption implies that the change of the logistic demand will directly react to the reverse demand curve. 
The revenue of a logistics park is directly affected by the potential logistics demand. The derived value from a logistics park is not defined because of the uncertainty of the annual potential logistic demand. To describe the change in potential logistic demand over time, we denote $q(t)$ as logistic demand of market at time $t$. Given that the logistics demand follows the geometric Brownian motion, which can be captured by $[23,24]$

$$
d q(t)=\eta q(t) d(t)+\sigma q(t) d \omega(t)
$$

where $\eta$ is the growth rate of logistics demand, $\sigma$ is the volatility rate of logistic demand, $d(t)$ is infinitesimal time increment, and $d \omega(t)$ is an increment of a standard Wiener process, for any given period $t, d \omega(t)$ satisfies the equation $d \omega(t)=\varepsilon_{t} \sqrt{\Delta t}$, where $\varepsilon_{t}$ is a random variable that follows the standard normal distribution of mean 0 and standard deviation 1 .

The value of investment is the duration of a project operation, which is equal to the corresponding expected discounted producer surplus. We let $\Gamma(q(t), M)$ denote the net present value of the project, which can be expressed as

$$
\begin{gathered}
\Gamma(q(t), M)=E\left[\int_{\Delta}^{+\infty}\left(\xi M+r M^{\rho}\right) e^{-k t} d t\right. \\
\left.-\int_{0}^{\Delta} C_{L} e^{-k t} d t-\int_{\Delta}^{+\infty} C_{O} e^{-k t} d t\right],
\end{gathered}
$$

where $\Delta$ is the duration of the entire construction project, which is assumed to be a constant in this study, and $r$ is the coefficient of unit government subsidy.

By calculating (5), we can obtain the following equation (the proof procedure is shown in Appendix A).

$$
\begin{aligned}
& \Gamma(q(t), M) \\
& \quad=\frac{M e^{(\eta-k) \Delta}}{k-\eta} q(t) \\
& \quad+\frac{(r-\omega) M^{\rho} e^{-k \Delta}-\gamma M^{2} e^{-k \Delta}-\lambda M^{\rho}\left(1-e^{-k \Delta}\right)}{k} .
\end{aligned}
$$

Equation (8) actually represents the Bellman equation for the option value $F(q(t))$. Applying Ito's lemma, we can determine the logistic demand threshold $q^{*}$ and the option value function $F(q(t))$, which are shown as in(9) and (10), respectively. The proof procedure is shown in Appendix B.

$$
\begin{aligned}
q^{*} & \frac{\alpha(k-\eta)\left[\gamma M e^{-k \Delta}+\lambda M^{\rho-1}\left(1-e^{-k \Delta}\right)+(\omega-r) M^{\rho-1} e^{-k \Delta}\right]}{k(\alpha-1) e^{(\eta-k) \Delta}}, \\
F(q(t), M) & = \begin{cases}\frac{\left(\gamma M^{2}+(\omega-r) M^{\rho}\right) e^{-k \Delta}+\lambda M^{\rho}\left(1-e^{-k \Delta}\right)}{k(\alpha-1)}\left(\frac{q}{q^{*}}\right)^{\alpha}, & q<q^{*} \\
\frac{M e^{(\eta-k) \Delta}}{k-\eta} q(t)+\frac{(r-\omega) M^{\rho} e^{-k \Delta}-\gamma M^{2} e^{-k \Delta}-\lambda M^{\rho}\left(1-e^{-k \Delta}\right)}{k}, & q \geq q^{*}\end{cases}
\end{aligned}
$$

(1) When $q<q^{*}$, the best strategy is to defer the project investment due to smaller logistics demand. Waiting for the future optimal investment time is a sensible strategy, and the value of investment is the option value at that time.
(2) When $q \geq q^{*}$, investing immediately is the best action, and the value of making the investment is NPV.

There are several methods for determining the optimal size of logistics park. The first method maximizes the intrinsic 
value of the project. The second method which selects the optimal size of the logistics park by maximizing the option value determines the capital density of investment. The third method is to determine the optimal size and the optimal output based on the corresponding maximal net present value (NPV). The first method may be better because the option value is equal to the intrinsic value at the moment of investment, while the value of the second choice is the option value before investment. The net present value is more suitable for the deterministic environment, but it ignores the opportunity cost in the process of investment in an uncertain environment. Therefore, this paper adopted the first method to determine the optimal size of a logistics park.
Let $V(q)$ be the intrinsic value at the state of implementing the option. That is,

$$
\begin{aligned}
V(q) & =\max _{M}\left\{\frac{M e^{(\eta-k) \Delta}}{k-\eta} q(t)\right. \\
& \left.+\frac{(r-\omega) M^{\rho} e^{-k \Delta}-\gamma M^{2} e^{-k \Delta}-\lambda M^{\rho}\left(1-e^{-k \Delta}\right)}{k}\right\} .
\end{aligned}
$$

The optimal size of a logistics park must satisfy the firstorder condition of (12) in order to maximize the intrinsic value:

$$
\frac{(2-\alpha) \gamma M e^{-k \Delta}+[\alpha-\rho(\alpha-1)]\left((\omega-r) e^{-k \Delta}+\lambda\left(1-e^{-k \Delta}\right)\right) M^{\rho-1}}{k(\alpha-1)}=0 .
$$

Calculating (9) and (12), we can obtain the optimal investment size of a logistics park and the investment demand threshold as the follows:

$$
\begin{aligned}
& M^{*}=\left(\frac{[\rho(\alpha-1)-\alpha]\left[(\omega-r) e^{-k \Delta}+\lambda\left(1-e^{-k \Delta}\right)\right]}{(2-\alpha) \gamma e^{-k \Delta}}\right)^{1 /(2-\rho)} \\
& q^{*}=\frac{\alpha(k-\eta)(\rho-2) \gamma e^{-k \Delta}}{k[\rho(\alpha-1)-\alpha] e^{(\eta-k) \Delta}}\left(\frac{[\rho(\alpha-1)-\alpha]\left[(\omega-r) e^{-k \Delta}+\lambda\left(1-e^{-k \Delta}\right)\right]}{(2-\alpha) \gamma e^{-k \Delta}}\right)^{1 /(2-\rho)} .
\end{aligned}
$$

As we know, the optimal investment size should be positive. In other words, the parameters in (13) and (14) need to satisfy the following conditions:

$$
\begin{array}{r}
\rho(\alpha-1)-\alpha>0, \quad \rho-2>0,2-\alpha>0 \\
\text { or } \rho(\alpha-1)-\alpha<0, \quad \rho-2<0,2-\alpha<0 .
\end{array}
$$

Solving these two inequalities, we know that the parameters need to meet the conditions $\rho>\alpha /(\alpha-1)$ and $\alpha<2$ or meet the conditions $\rho<\alpha /(\alpha-1)$ and $\alpha>2$.

Given the model parameters, we can obtain the relationship between logistics demand under NPV and RO approaches from (7) and (9), as follows:

$$
q^{*}=\frac{\alpha}{\alpha-1} q_{\mathrm{NPV}}^{*} \text {. }
$$

Equation (16) implies that the logistic demand under the $\mathrm{RO}$ approach is always larger than that under the NPV approach because the $\mathrm{RO}$ approach incorporates the value of flexibility through the option to wait and defer investment.

2.3. Static Analysis of Threshold of Logistics Demand. The effects of key model parameters, such as interest rate $k$, construction period $\Delta$, logistic demand $\sigma$, government subsidy $r$, sensitive coefficient $\gamma$, and the change rate of demand $\eta$ are investigated. In accordance with (13), the following inequalities will hold, $\partial M^{*} / \partial \sigma>0, \partial M^{*} / \partial \Delta>0, \partial M^{*} / \partial r<$ 0 , and $\partial M^{*} / \partial \gamma<0$. Similarly, we can find that $\partial q^{*} / \partial \sigma>0$ and $\partial q^{*} / \partial r<0$; however, the symbols of $\partial q^{*} / \partial \Delta$ and $\partial q^{*} / \partial \gamma$ are difficult to determine. The proof procedure is shown in Appendix C.

The signs of $q^{*}$ and $M^{*}$ with regard to the growth rate of logistics demand and discount rate (i.e., $\partial q^{*} / \partial \eta, \partial q^{*} / \partial k$, $\partial M^{*} / \partial \eta$ and $\left.\partial M^{*} / \partial k\right)$ are also difficult to determine analytically. Therefore, a simulation method is used to ascertain their relations in the later numerical example.

\section{Case Study}

3.1. Data and Parameter Settings. In this section, two test examples are used to illustrate the application model and the contribution of this study. The first example is designed to reveal the effect on the investment of a logistics park with and without consideration of government subsidies. The effect of the key model parameters (e.g., the growth rate of the demand, discount rate, the construction of the project, and the demand volatility) on the trigger logistics demand threshold and the optimal investment size are also investigated. 
TABLE 1: Freight transportation volume of Changsha City.

\begin{tabular}{lc}
\hline Year & Freight transportation volume (million tons) \\
\hline 2000 & 59.10 \\
2001 & 75.50 \\
2002 & 87.66 \\
2003 & 106.32 \\
2004 & 110.66 \\
2005 & 109.91 \\
2006 & 124.78 \\
2007 & 161.84 \\
2008 & 171.58 \\
2009 & 210.74 \\
2010 & 229.47 \\
2011 & 256.51 \\
2012 & 261.45 \\
2013 & 280.48 \\
2014 & 304.49 \\
\hline
\end{tabular}

Source. Changsha Statistical Yearbook (2000-2014) [9].

The second example illustrates the real application of the proposed model for Jinxia logistics park project located in Changsha, Hunan Province. We can obtain the investment timing and the optimal size of the logistics park to confirm the validity of the model. Table 1 provides statistics data of logistics service demand of Changsha City from 2000 to 2014. Table 2 shows the other input parameters.

3.2. Simulation Results and Analysis. In Section 3.2.1, we address the effect of government subsidies to the logistic demand that triggers the threshold of investment in a logistics park under the RO and NPV approaches. The effects of the key model parameters are analyzed. Moreover, we examine the optimal investment timing for different sizes of logistics parks under the RO and NPV methods in Section 3.2.2.

3.2.1. Comparison of Investment Decisions with and without Government Subsidies under the RO and the NPV Methods. Figure 1 describes the difference between the curves for option value and NPV, which can be calculated by (6) and (10), respectively. In Figure 1, intersection points $D_{1}$ and $D_{2}$ between the NPV curve and the horizontal line represent demand threshold $Y_{\mathrm{NPV}}^{*}$ in the NPV approach in terms of (7).

Intersection points $E_{1}$ and $E_{2}$ between the curves for the option value and NPV of a given logistics park size represent logistics demand $Y^{*}$ under the RO approach in accordance with (9). The solutions for demand and size threshold under the RO and NPV approaches are shown in Table 3.

The main insights obtained from Figure 1 and Table 3 are summarized as follows.

First, ignoring the effects of the government subsidy on the construction of logistics parks will lead to a later investment due to an underestimation of investment benefits or returns. We take the RO solution as an example. When considering government subsidies, the trigger logistics demand threshold $q^{*}$ for the logistics park is 472.22 million tons per year, denoted by point $E_{1}$ in Figure 1 . The corresponding
TABLE 2: Input parameters for model application.

\begin{tabular}{|c|c|c|}
\hline Parameter & Definition & Baseline value \\
\hline$\rho$ & Parameters of scale economic effect & 0.900 \\
\hline$\beta$ & Parameters in the service charge & 0.800 \\
\hline$\gamma$ & $\begin{array}{l}\text { The sensitivity of the service charge } \\
\text { to the size of logistic park }\end{array}$ & 6.000 \\
\hline$r$ & $\begin{array}{l}\text { Government subsidy (million } \\
\mathrm{RMB} / \text { million tons) }\end{array}$ & 0.580 \\
\hline$\eta$ & Growth rate of logistics demand & 0.011 \\
\hline$\sigma$ & $\begin{array}{l}\text { The volatility rate of logistics } \\
\text { demand }\end{array}$ & 0.190 \\
\hline$\lambda$ & $\begin{array}{l}\text { Unit construction cost (million } \\
\mathrm{RMB} / \text { million tons) }\end{array}$ & 15.000 \\
\hline$\omega$ & $\begin{array}{l}\text { Unit operating cost (million } \\
\mathrm{RMB} / \text { million tons) }\end{array}$ & 4.500 \\
\hline$\Delta$ & Construction duration (years) & 5.000 \\
\hline$k$ & Discount rate & 0.060 \\
\hline
\end{tabular}

(Source. Data adapted from Li et al. [10] and Zhang et al. [3]).

TABLE 3: Demand threshold with and without consideration of government subsidies under the RO and NPV models.

\begin{tabular}{lcc}
\hline Government subsidy & Method & $q^{*}$ (million tons) \\
\hline \multirow{2}{*}{$r=0$} & NPV & 252.21 \\
& RO & 499.30 \\
$r=0.58$ & NPV & 239.48 \\
& RO & 472.22 \\
\hline
\end{tabular}

value of $q^{*}$ without the government subsidy is 499.30 million tons. Similar results can be observed for the NPV solution. However, the curves for the option value with and without consideration of the government subsidy reach coincidence, as noted in Figure 1. The optimal size of a logistics park and the logistic demand threshold with a government subsidy are smaller than the threshold where the government subsidy is ignored. It can be seen from (10) that the size of logistics park is in direct proportion to the option value and the demand threshold is inversely proportionate to the option value. Therefore, the overlap of positive impact of $q^{*}$ and the negative impact of $M$ makes the small change of the option value with and without considering the government subsidy.

Second, the demand threshold calculated through the RO method is higher than that obtained through the NPV method. The opportunity cost during the entire investment process is considered in the RO method because the uncertainty of logistics demand and the irreversibility of logistics park projects. Generally speaking, the opportunity cost is highly sensitive to uncertainty over the future logistics demand. The greater the uncertainty, the greater the opportunity cost. This implies that the investors should adjust the strategic investments according to changes in the uncertain logistics demand environment in order to enhance the investment value of project.

3.2.2. Effects of Key Parameters on Demand Threshold and the Optimal Size of a Logistics Park. The analysis of the effects of 


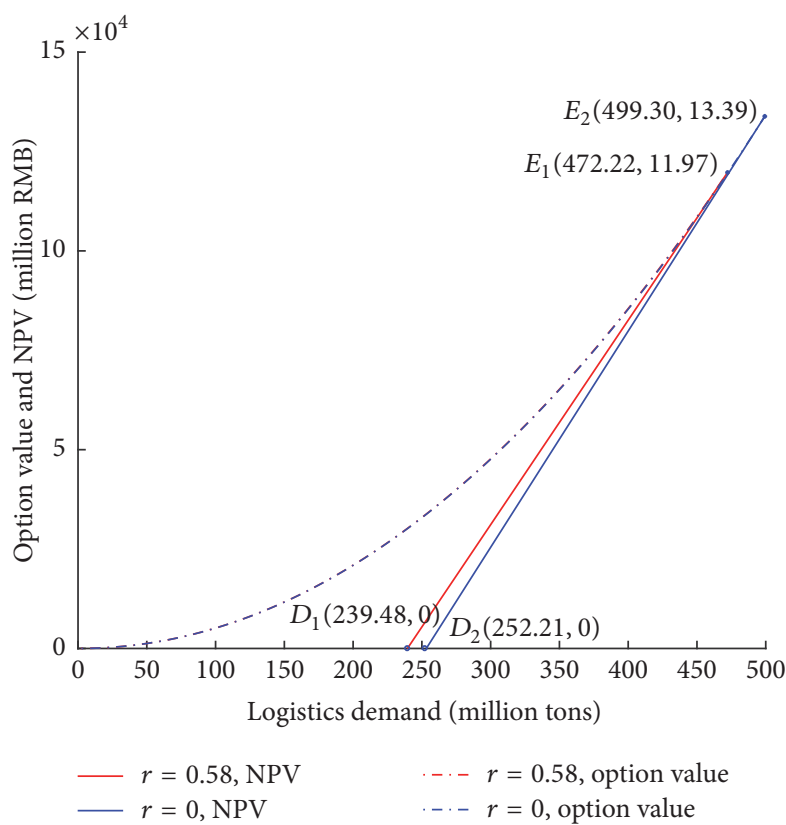

FIGURE 1: Option value curves and NPV value curves with different government subsidies.

key model parameters for triggering the investment threshold in logistics parks is as follows.

(1) Effects of Demand Growth Rate and Logistics Demand Volatility on Demand Threshold and the Optimal Size of a Logistics Park. Figures 2 and 3 plot the change in logistics demand threshold and optimal size of the logistics park as the growth rate of demand and demand volatility change, respectively. The plots show that the trigger for demand threshold and the optimal investment size for a given growth rate and volatility of logistics demand and vice versa. A greater growth rate of the demand means a greater growth rate of the logistic demand; therefore, investors will wait for a greater demand to invest in order to gain greater option value. Similarly, when demand volatility increases under a fixed growth rate, the trigger for the demand threshold and the optimal investment size also increases. In other words, when investors are faced with greater uncertainty, they will postpone investment and invest a larger size logistics park. This trend may be attributed to the notion that increased demand volatility denotes higher uncertainty in the investment environment and increased the option value of investment in a logistics park. During this period, deferring investment is a better strategy than immediate investment.

(2) Effects of the Discount Rate and the Duration of Construction on Demand Threshold and the Optimal Size of a Logistics Parks. Figures 4 and 5 show the effects of the discount rate and the duration of construction on demand threshold and the optimal investment size, respectively. For a given discount rate, the threshold of logistics demand and corresponding investment size will become larger with the increase of the duration of construction on a logistics park. A long

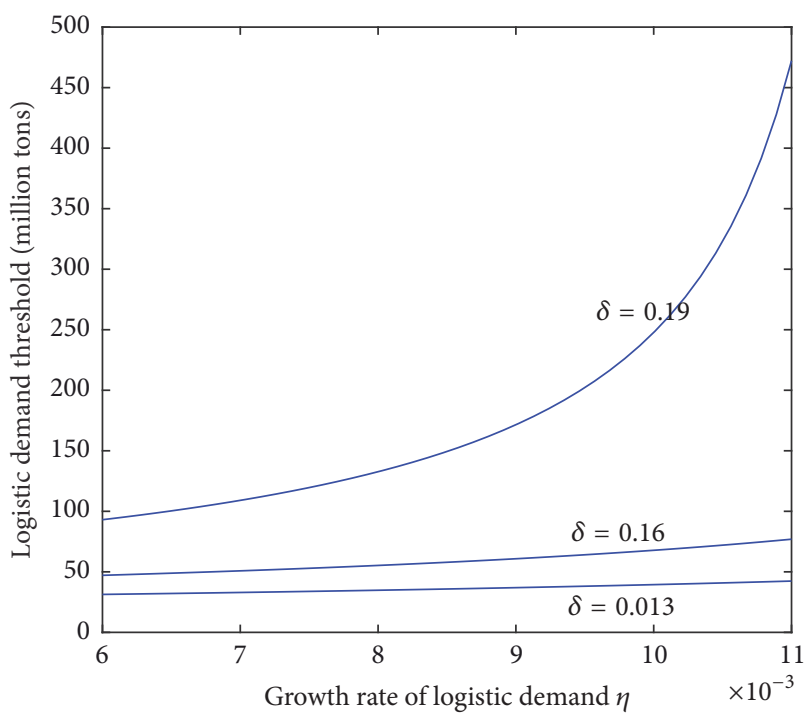

FIGURE 2: Change of the logistic demand threshold with the growth rate of logistic demand and volatility.

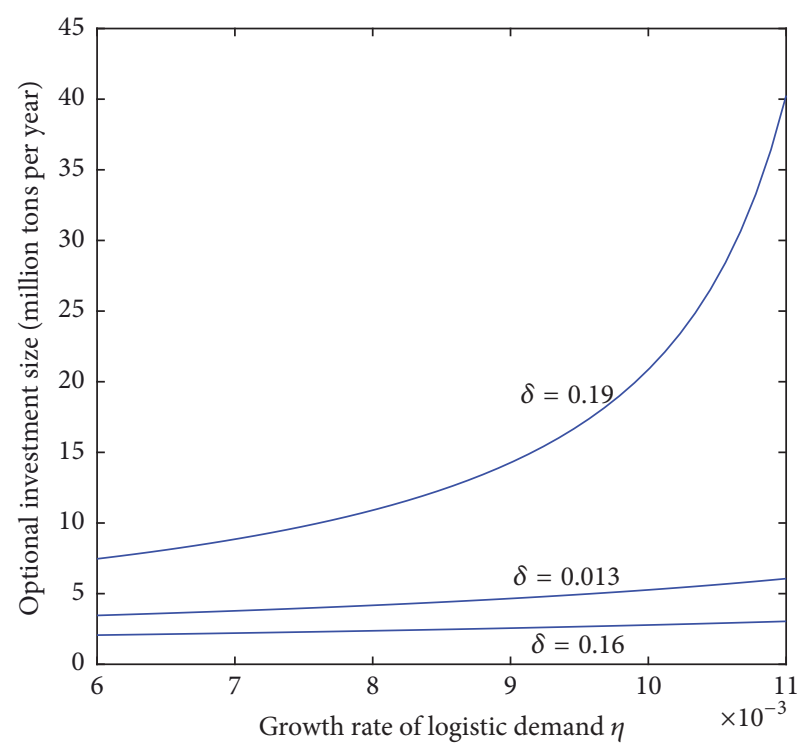

FIGURE 3: Change of the optimal size with the growth rate of logistic demand and volatility.

duration of construction implies a high cost of investment opportunity, which reduces the appeal of the investment project. Postponing the investment and selecting a larger logistics park to invest in are a better strategy. Moreover, for a given duration of construction, the demand threshold and optimal investment size will decrease sharply with the increasing of discount rate and then increase slightly with the increasing of discount rate. This implies that a wise decision is to invest a larger size logistics park project earlier, so as to reduce the investment cost in this case.

(3) Effects of Sensitive Coefficient and Government Subsidies on Demand Threshold and the Optimal Size of a Logistics Park. Figures 6 and 7 plot the change of the demand threshold and 


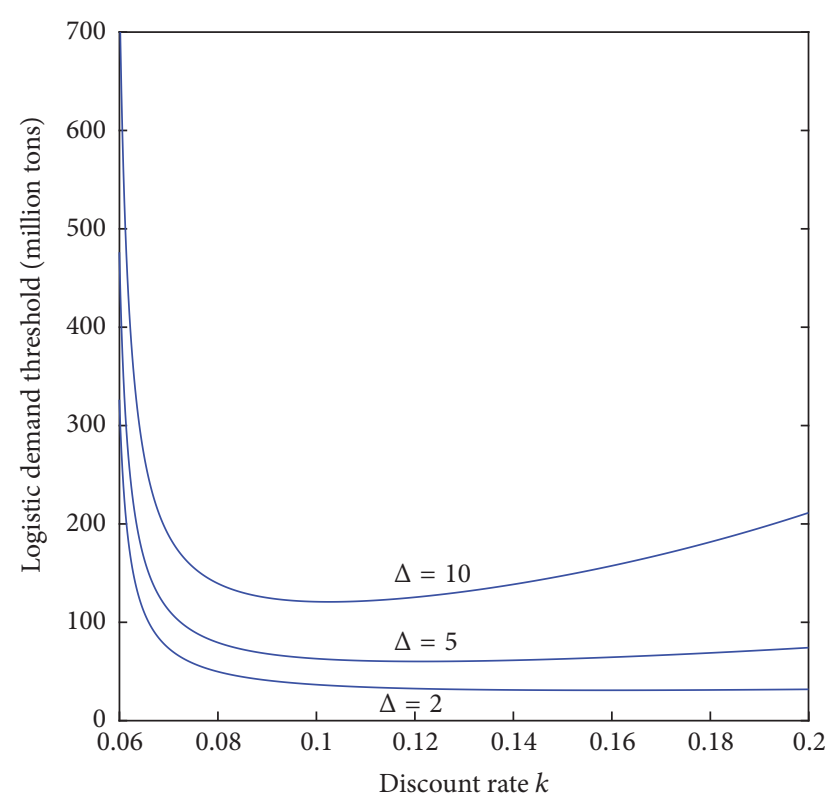

FIgURE 4: Change of the logistics demand threshold with the discount rate and project construction duration.

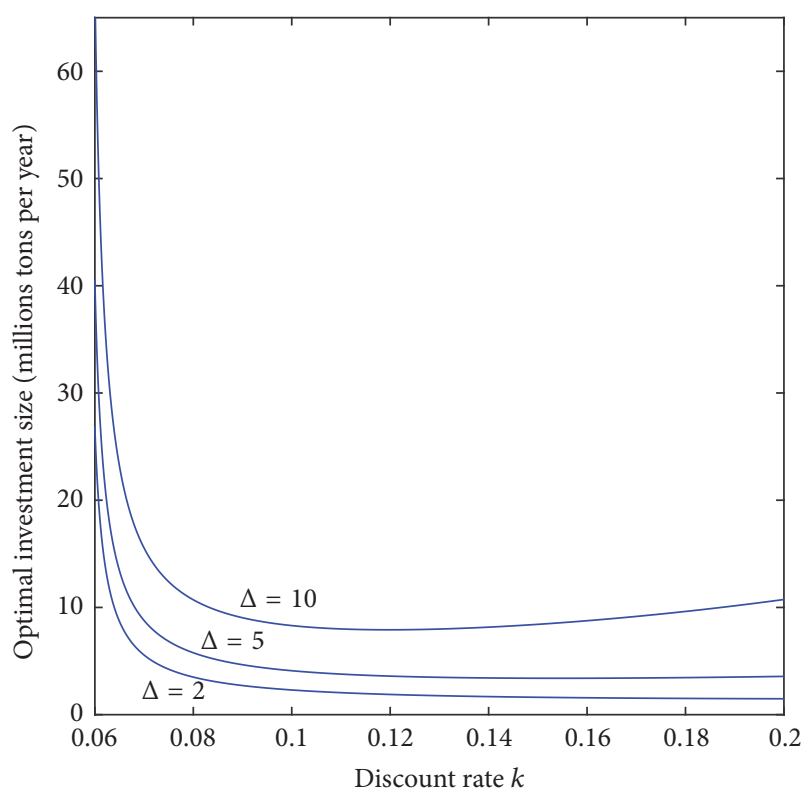

FIGURE 5: Change of the optimal size with the discount rate and project construction duration.

the optimal investment size as the sensitive coefficient and government subsidy change. For a given sensitive coefficient, the trigger demand threshold and the optimal investment size decrease with an increase in the government subsidy level. This means that investors will choose smaller sizes of logistics parks and invest earlier if the government gives a larger subsidy. In contrast, for a fixed government subsidy, as the sensitive coefficient increases, the trigger demand threshold decreases, and the optimal investment size of logistics park decreases, according to (13) and (14). An increase in the

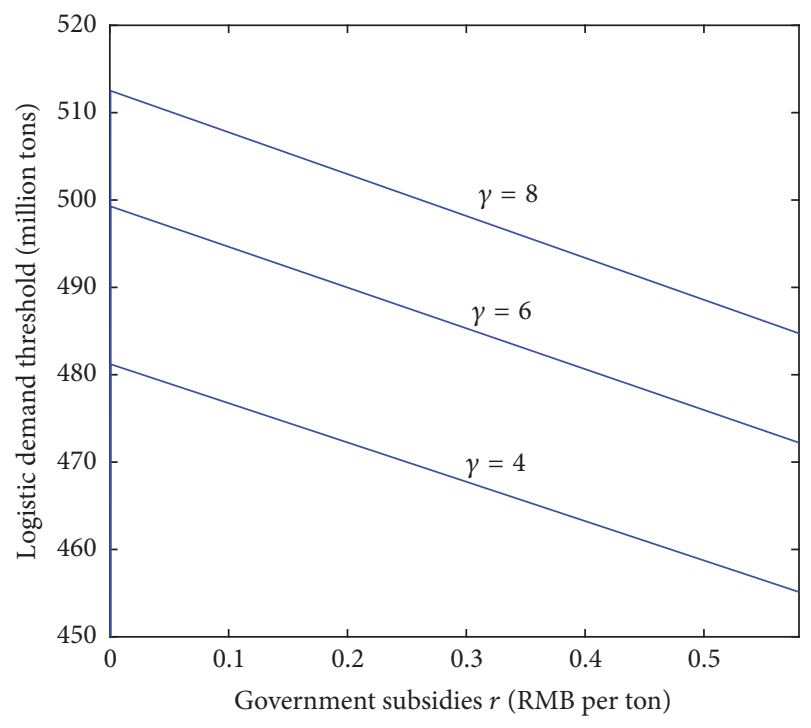

FIGURE 6: Change of the logistics demand threshold with government subsidies.

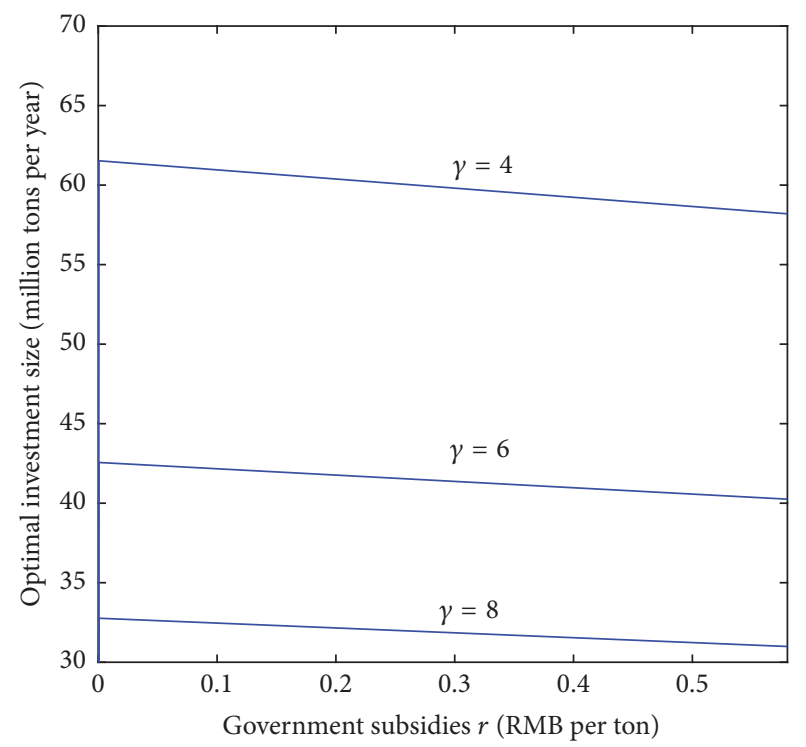

FIGURE 7: Change of the optimal size with government subsidies.

sensitive coefficient leads to the decrease of trigger demand threshold and size of logistics parks. Deferring investments and selecting a smaller size for investment comprise a better strategy than immediate investment.

3.2.3. Analysis of Optimal Timing and Size of a Logistics Park Investment. For further illustration, we apply the proposed logistics park investment model to a real-world case, Jinxia logistics park project located in Changsha, Hunan, China. We assume that since 2014, the change in the logistic demand of the market over time follows a geometric Brownian motion. Without the loss of generality, we generate three trajectories (or paths) of the logistic demand size over time according to 


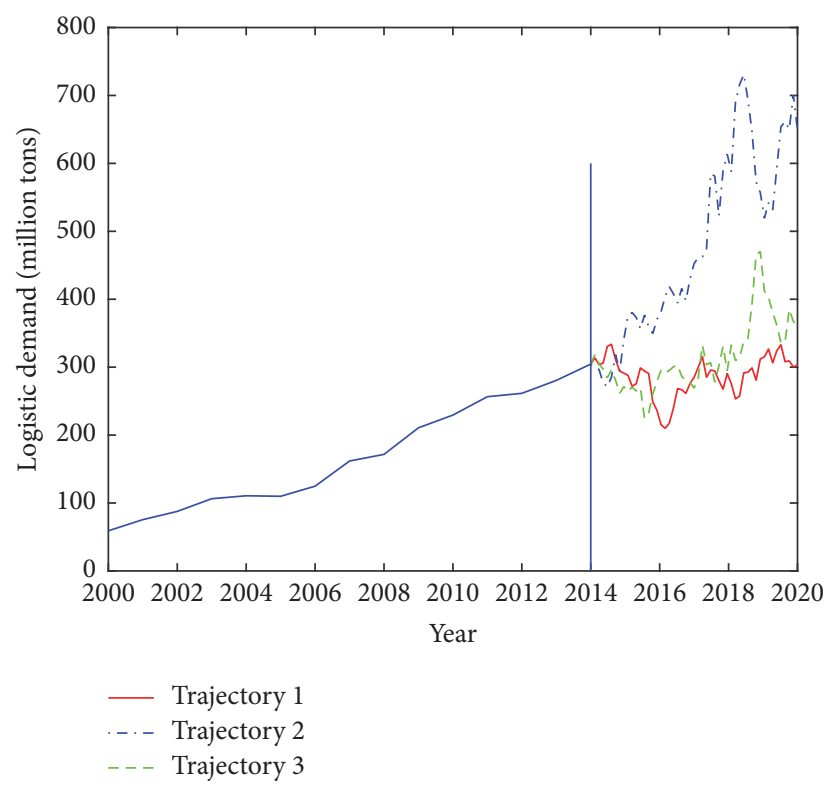

FIGURE 8: Actual and simulated logistics demand between 2000 and 2020.

the geometric Brownian motion, as indicated on the righthand side of Figure 8.

We examine the optimal timing of investment and investment size in logistics parks using the NPV and RO methods.

Figures 9 and 10 show that the change curves of the annual option value and annual NPV with and without government subsidy consideration, respectively. Figure 9 shows that the option value and NPV curves intersect at point $Q$, which is associated with an investment in 2020.00. This investment yields a project value of RMB 119.70 billion at the optimal investment size of 40.25 million tons. Point $Q$ is the result estimated with the RO approach in terms of (14), and the optimal investment size is estimated with the RO approach in terms of (13). Figure 9 also shows that the NPV curves intersect with the horizontal axis at point $P$, which is the result estimated with the NPV approach in terms of (7). This intersection suggests investment timing in 2010.40 with a logistic demand of 239.48 million tons. Similarly, Figure 10 shows that the optimal investment decision generated with the RO approach occurs at point $F$, with investment in 2021.00 and an optimal investment size of 42.56 million tons and a project value of RMB 133.90 billion. The optimal investment timing generated with the NPV approach is 2010.85 , which is associated with point $E$.

Table 4 summarizes the estimated optimal investment timing and optimal investment size for logistics parks under the RO and NPV approaches. The NPV approach induces earlier investments than the RO approach at 9.60 years and 10.15 years with and without government subsidy considerations, respectively. In addition, government subsidies will stimulate investors to select smaller sizes of logistics parks for investment.

In Figures 9 and 10, we calculate and compare the total project values accrued from the optimal timing of investment

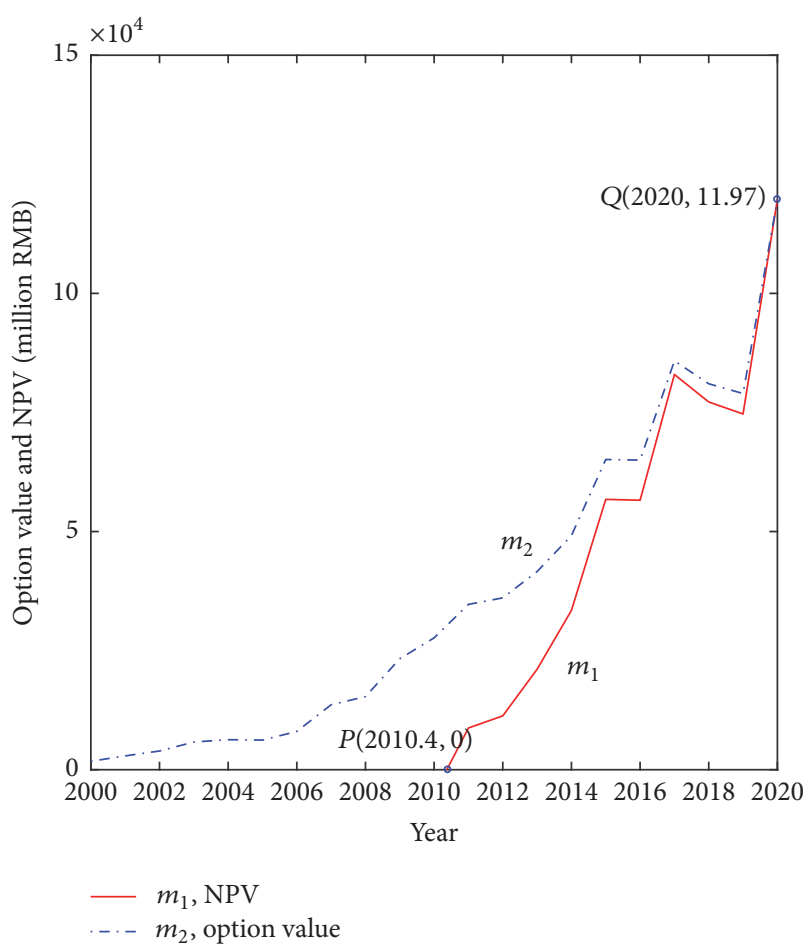

FIGURE 9: Option value and NPV of introducing different sizes of logistics parks with government subsidies.

TABLE 4: Estimated timing of investment and optimal investment size in logistics park.

\begin{tabular}{lccc}
\hline $\begin{array}{l}\text { Government } \\
\text { subsidy }\end{array}$ & Method & $\begin{array}{c}\text { Estimated investment } \\
\text { timing (year) }\end{array}$ & $\begin{array}{c}\text { Optimal investment } \\
\text { size (million tons) }\end{array}$ \\
\hline$r=0$ & NPV & 2010.85 & - \\
& RO & 2021.00 & 42.56 \\
$r=0.58$ & NPV & 2010.40 & - \\
& RO & 2020.00 & 40.25 \\
\hline
\end{tabular}

using the NPV approach compared with that obtained by the RO approach. We also determine the corresponding loss in the project values because the timing of investment occurs at the time estimated with the NPV approach but not at that estimated with the RO approach. The total loss of project value is equal to RMB 119.70 billion and $\mathrm{RMB}$ 133.90 billion when the NPV approach is used instead of the RO approach with and without government subsidy considerations, respectively. The corresponding difference on total loss of the project value is equal to RMB 14.20 billion. These results further illustrate that the RO approach compensates for the defect of the NPV approach. The RO approach is more effective for investors than NPV when estimating the optimal investment time for logistics parks. Moreover, government subsidies will affect the decision of investors.

3.3. Managerial Recommendations. There are several key results of this research that have direct managerial implications. Results show that the government subsidy, volatility of 


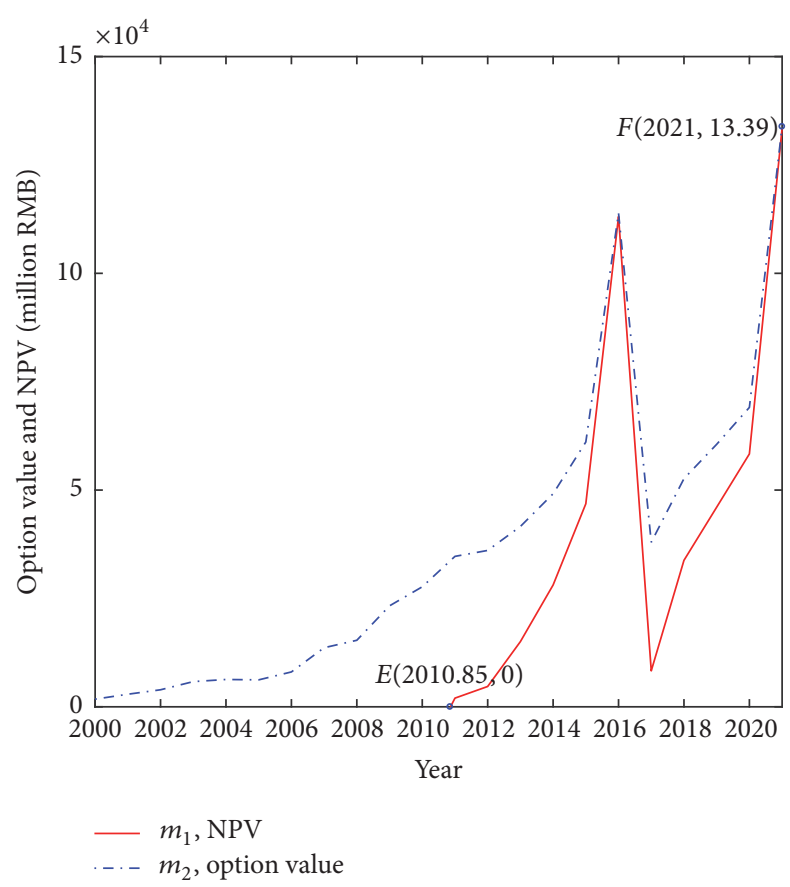

FIGURE 10: Option value and NPV of introducing different sizes of logistics parks without government subsidies.

logistics demand, duration of construction, and discount rate have significant impacts on timing and size of logistics park project investment.

First, investors should carefully analyze the growth rate and volatility of logistics parks before they invest a logistics park project. In highly volatility logistics service market, choosing a larger size (i.e., a higher trigger threshold of logistics demand) becomes even more important, which will benefit to obtain more real option value. In other words, when investors are faced with greater uncertainty, they will postpone investment and invest a larger size logistics park. For a fixed volatility of logistics demand, the size of a candidate logistics park will slightly increase with the increase of the growth rate of logistics demand. On the contrary, the size of a candidate logistics park increases sharply with the increase of the volatility of logistics demand under a fixed logistics demand growth rate. This implies that the investors should determine a rational invest timing and size based on the analysis of the logistics demand growth rate and volatility, which are close related to development trend of regional economic and industrial structure.

Second, ignoring the effects of the government subsidy on the construction of logistics parks will lead to a later investment due to an underestimation of investment benefits or returns. This means that the optimal size of a logistics park and the logistic demand threshold with a government subsidy are smaller than the threshold where the government subsidy is ignored. Hence, the governments should provide some subsidy to promote city logistics efficiency and decrease the negative effects (e.g., traffic congestions and $\mathrm{CO}_{2}$ emissions) by inducing logistics park projects. But it should be kept in mind that the higher subsidy leads to a smaller project, in which less economies of scale in the construction and operator exist.

Third, investors should keep in mind that discount rate and duration of construction have some impacts to invest timing and size of logistics parks. For a given discount rate, the threshold of logistics demand and corresponding investment size will become larger with the increase of the duration of construction on a logistics park. Postponing the investment and selecting a larger logistics park to invest in is a better strategy. Moreover, for a given duration of construction, the demand threshold and optimal investment size will decrease sharply with the increasing of discount rate and then increase slightly with the increasing of discount rate. This implies that a wise decision is to invest a larger size logistics park project early, so as to reduce the investment cost in this case.

Lastly, improving the economies of scale of logistics parks operator will decrease unit transfer charge, which leads to the decrease of trigger demand threshold and size of logistics parks. This implies that the investors should improve the logistics operator efficiency by logistics clustering and logistics service innovation methods, so as to achieve the economies of scale of logistics park operator.

\section{Conclusion and Future Studies}

This paper proposed an $\mathrm{RO}$ model to address size selection problems in logistics park investments by considering the uncertainty of the logistic demand of a city. The properties of the proposed model are explored analytically, including triggering demand thresholds for investment, optimal investment size in logistics parks, and the impact of government subsidies on investors. The impact of government subsidies and comparative static analyses of investment in logistics park were calculated. To illustrate the application of the proposed model, we use a logistics park in Changsha as an example. The investment decisions for a logistics park with the RO approach are compared with that of the NPV approach. The loss in project value caused by the NPV approach was estimated, but not the loss caused by the RO approach.

The proposed model offers new insights and important findings. First, the investment benefit curves of logistics parks significantly differ between the NPV and RO approaches. Compared with the RO approach, the NPV approach underestimates the value of investment in a logistics park, which results in premature investment and therefore loss in project value. Second, investors will select smaller investment sizes earlier if the government gives subsidy to the project whether it is considered an NPV approach or RO approach. Third, the optimal timing of investment and optimal investment size in a logistics park are dependent on the duration of construction, discount rate, rate of demand change, government subsidy, and demand volatility. The proposed methodology can serve as a useful tool for making decisions with regard to investing in a logistics park.

Although the proposed model provides useful insights for logistics park investment decisions, we recommend the following points for future study. 
(1) The correlation effect between different areas in a city was not explicitly considered in the logistics park investment problem. The logistic demands in each area of a city influence each other, and establishing a logistics park in one area affects investments in others. This phenomenon limits the $\mathrm{RO}$ approach in uncertain environments. However, game theory can adjust investment strategy in accordance with the investment behaviors of competitors. Therefore, introducing game theory into the $\mathrm{RO}$ approach as investment strategy in a logistics park is scientifically sound and reasonable.

(2) In this study, the variation of demand logistics demand of a city is considered the major source of uncertainty that influences investment decisions in a logistics park. Other sources of uncertainty, such as population size and attitude of decision-makers, should also be studied. These factors affect the returns on investment in a logistics park. Incorporating the investment risk derived from other sources of uncertainty is important in determining the mode of logistics investment.

\section{Conflicts of Interest}

The authors declare that they have no conflicts of interest.

\section{Acknowledgments}

The work that is described in this paper was supported by Central South University Teacher Research Fund (no. 2015), Hunan Province Science and Technology Development Funds (no. 2015RS4045), Excellent Youth Project of Hunan Provincial Department of Education (no. 15B261), Graduate Education and Degree innovation Foundation of Central South University (no. 2014JGB36), and National Natural Science Foundation of China (nos. 71672193 and 71403096).

\section{Supplementary Materials}

Supplementary proof of (6) related to this article can be found in Appendix A. Supplementary proof of (7) and (10) related to this article can be found in Appendix B. Supplementary proof of static analysis for the thresholds $q^{*}$ and $M^{*}$ related to this article can be found in Appendix C. (Supplementary Materials)

\section{References}

[1] Y. Wang, X. L. Ma, Y. T. Lao, and Y. H. Wang, "A fuzzy-based customer clustering approach with hierarchical structure for logistics network optimization," Expert Systems with Applications, vol. 41, no. 2, pp. 521-534, 2014.

[2] A. C. McKinnon, "Green logistics: the carbon agenda, Electronic Scientific Journal of Logistics, vol. 6, no. 3, article 1, 2010, http://www.logforum.net/pdf/6_3_1_10.pdf.

[3] D. Zhang, R. Eglese, and S. Li, "Optimal location and size of logistics parks in a regional logistics network with economies of scale and $\mathrm{CO}_{2}$ emission taxes," Transport, 2015.

[4] D. Wu, Y. F. Yin, and S. Lawphongpanich, "Pareto-improving congestion pricing on multimodal transportation networks,"
European Journal of Operational Research, vol. 210, no. 3, pp. 660-669, 2011.

[5] Q. Dai and J. Yang, "Input-output analysis on the contribution of logistics park construction to regional economic development," Procedia - Social and Behavioral Sciences, vol. 96, pp. 599-608, 2013.

[6] D. A. King, C. E. Gordon, and J. R. Peters, "Does road pricing affect port freight activity: Recent evidence from the port of new york and new jersey," Research in Transportation Economics, vol. 44, no. 1, pp. 2-11, 2014.

[7] Purchasing CFoLa, "The Fifth Survey report on Logistics Parks in China," 2015, http://www.cflp.org.cn/.

[8] L. Rivera, Y. Sheffi, and D. Knoppen, "Logistics clusters: The impact of further agglomeration, training and firm size on collaboration and value added services," International Journal of Production Economics, vol. 179, pp. 285-294, 2016.

[9] Bureau of Statistics of Changsha, Changsha Statistical Yearbook (2000-2014), China Statistics Press, Beijing, China, 2015 (Chinese).

[10] Z.-C. Li, Q.-W. Guo, W. H. K. Lam, and S. C. Wong, “Transit technology investment and selection under urban population volatility: A real option perspective," Transportation Research Part B: Methodological, vol. 78, pp. 318-340, 2015.

[11] E. Taniguchi, M. Noritake, T. Yamada, and T. Izumitani, "Optimal size and location planning of public logistics terminals," Transportation Research Part E: Logistics and Transportation Review, vol. 35, no. 3, pp. 207-222, 1999.

[12] C. Nguyen, M. Dessouky, and A. Toriello, "Consolidation strategies for the delivery of perishable products," Transportation Research Part E: Logistics and Transportation Review, vol. 69, pp. 108-121, 2014.

[13] M. Soysal, J. M. Bloemhof-Ruwaard, and T. Bektaş, “The timedependent two-echelon capacitated vehicle routing problem with environmental considerations," International Journal of Production Economics, vol. 164, pp. 366-378, 2015.

[14] J. G. V. Vieira, J. C. Fransoo, and C. D. Carvalho, "Freight distribution in megacities: perspectives of shippers, logistics service providers and carriers," Journal of Transport Geography, vol. 46, pp. 46-54, 2015.

[15] J. X. Tang, L. X. Tang, and X. P. Wang, "Solution method for the location planning problem of logistics park with variable capacity," Computers \& Operations Research, vol. 40, no. 1, pp. 406-417, 2013.

[16] Y. R. Chen, Y. S. Jiang, M. I. M. Wahab, and X. Q. Long, "The facility layout problem in non-rectangular logistics parks with split lines," Expert Systems with Applications, vol. 42, no. 21, pp. 7768-7780, 2015.

[17] L. Rivera, Y. Sheffi, and R. Welsch, "Logistics agglomeration in the US," Transportation Research Part A: Policy and Practice, vol. 59, pp. 222-238, 2014.

[18] J. Zacharias and B. Zhang, "Local distribution and collection for environmental and social sustainability - tricycles in central Beijing," Journal of Transport Geography, vol. 49, pp. 9-15, 2015.

[19] A. C. McKinnon, S. Cullinane, M. Browne, and A. Whiteing, Green Logistics: Improving the Environmental Sustainability of Logistics, Kogan Page Ltd, 2012.

[20] S. J. Sadjadi, R. Soltani, and A. Eskandarpour, "Location based treatment activities for end of life products network design under uncertainty by a robust multi-objective memetic-based heuristic approach," Applied Soft Computing, vol. 23, pp. 215226, 2014. 
[21] A. Rudi, M. Fröhling, K. Zimmer, and F. Schultmann, "Freight transportation planning considering carbon emissions and intransit holding costs: a capacitated multi-commodity network flow model," EURO Journal on Transportation and Logistics, vol. 5, no. 2, pp. 123-160, 2016.

[22] C. J. Rao, M. Goh, Y. Zhao, and J. J. Zheng, "Location selection of city logistics centers under sustainability," Transportation Research Part D: Transport and Environment, vol. 36, pp. 29-44, 2015.

[23] A. Dixit and R. Pindyck, Investment under Uncertainty, Princeton University Press, Princeton, NJ, USA, 1994.

[24] R. McDonald and D. Siegel, "The value of waiting to invest," The Quarterly Journal of Economics, vol. 101, no. 4, pp. 707-727, 1986.

[25] A. T. Chen, Z. Zhou, P. Chootinan, S. Ryu, C. Yang, and S. C. Wong, "Transport network design problem under uncertainty: a review and new developments," Transport Reviews, vol. 31, no. 6, pp. 743-768, 2011.

[26] J. Y. J. Chow and H. R. Sayarshad, "Reference policies for non-myopic sequential network design and timing problems," Networks \& Spatial Economics, vol. 16, no. 4, pp. 1183-1209, 2016.

[27] J. Y. J. Chow, A. C. Regan, F. Ranaiefar, and D. I. Arkhipov, "A network option portfolio management framework for adaptive transportation planning," Transportation Research Part A: Policy and Practice, vol. 45, no. 8, pp. 765-778, 2011.

[28] J. Y. J. Chow and A. C. Regan, "Network-based real option models," Transportation Research Part B: Methodological, vol. 45, no. 4, pp. 682-695, 2011.

[29] Y.-B. Xiao, X. Fu, T. H. Oum, and J. Yan, "Modeling airport capacity choice with real options," Transportation Research Part B: Methodological, vol. 100, pp. 93-114, 2017.

[30] Y. L. Gao and T. Driouchi, "Incorporating Knightian uncertainty into real options analysis: using multiple-priors in the case of rail transit investment," Transportation Research Part B: Methodological, vol. 55, pp. 23-40, 2013.

[31] Y. H. Li, C.-L. Tseng, and G. P. Hu, "Is now a good time for Iowa to invest in cellulosic biofuels? A real options approach considering construction lead times," International Journal of Production Economics, vol. 167, pp. 97-107, 2015.

[32] J. Y. J. Chow and H. R. Sayarshad, "Reference policies for non-myopic sequential network design and timing problems," Networks and Spatial Economics, vol. 16, no. 4, pp. 1183-1209, 2016.

[33] G. Cortazar, E. S. Schwartz, and M. Salinas, "Evaluating environmental investments: A real options approach," Management Science, vol. 44, no. 8, pp. 1059-1070, 1998.

[34] T. Bockman, S. Fleten, E. Juliussen, H. J. Langhammer, and I. Revdal, "Investment timing and optimal capacity choice for small hydropower projects," European Journal of Operational Research, vol. 190, no. 1, pp. 255-267, 2008.

[35] T. K. Boomsma, N. Meade, and S.-E. Fleten, "Renewable energy investments under different support schemes: a real options approach," European Journal of Operational Research, vol. 220, no. 1, pp. 225-237, 2012.

[36] A. Welling, "The paradox effects of uncertainty and flexibility on investment in renewables under governmental support," European Journal of Operational Research, vol. 251, no. 3, pp. 1016-1028, 2016.

[37] S. Li and H. Cai, "Government incentive impacts on private investment behaviors under demand uncertainty," Transportation Research Part E: Logistics and Transportation Review, vol. 101, pp. 115-129, 2017.
[38] D. Zhang, Study on the Evolvement Mechanism and Layout Optimization Methods of Logistics Park, Central South University, Changsha, China, 2006.

[39] J. Berechman and G. Giuliano, "Economies of scale in bus transit: A review of concepts and evidence," Transportation, vol. 12, no. 4, pp. 313-332, 1985.

[40] Z.-C. Li, W. H. Lam, and S. C. Wong, "Optimization of number of operators and allocation of new lines in an oligopolistic transit market," Networks and Spatial Economics, vol. 12, no. 1, pp. 1-20, 2012.

[41] Z.-C. Li, W. H. K. Lam, and S. C. Wong, "On the allocation of new lines in a competitive transit network with uncertain demand and scale economies," Journal of Advanced Transportation, vol. 45, no. 4, pp. 233-251, 2011.

[42] D. Zhang, F. Zou, S. Li, and L. Zhou, "Green supply chain network design with economies of scale and environmental concerns," Journal of Advanced Transportation, vol. 2017, Article ID 6350562, 14 pages, 2017.

[43] H. Winkler and G. Seebacher, "An empirical investigation of german freight villages," Research in Logistics \& Production, vol. 2, pp. 399-410, 2012. 


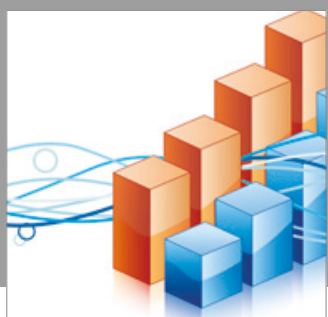

Advances in

Operations Research

vatersals

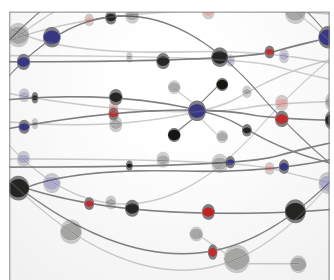

\section{The Scientific} World Journal
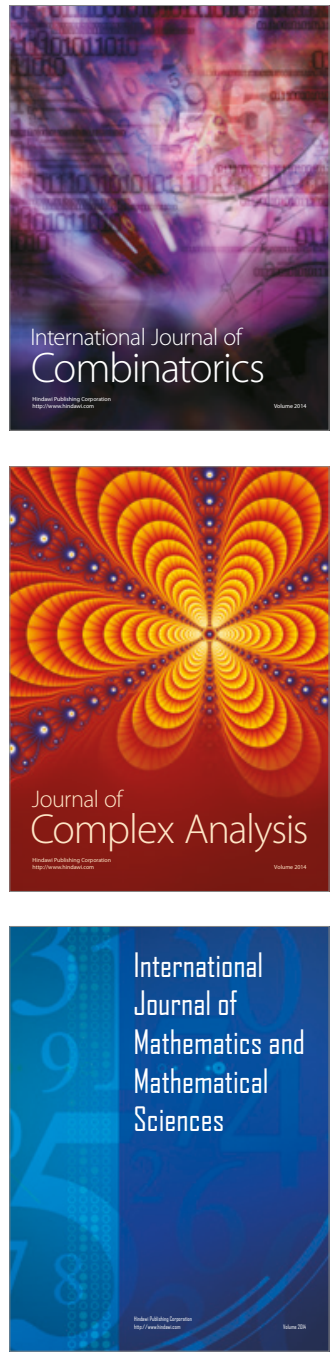
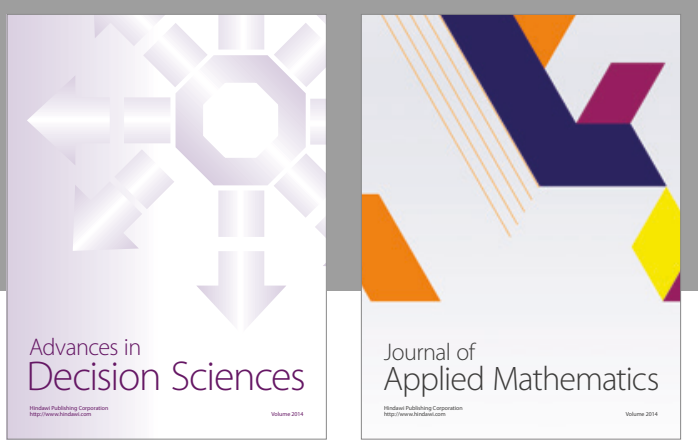

Algebra

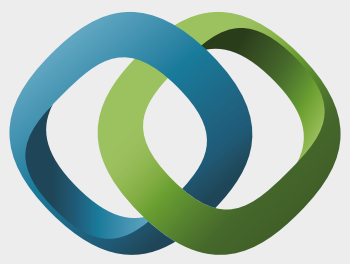

\section{Hindawi}

Submit your manuscripts at

https://www.hindawi.com
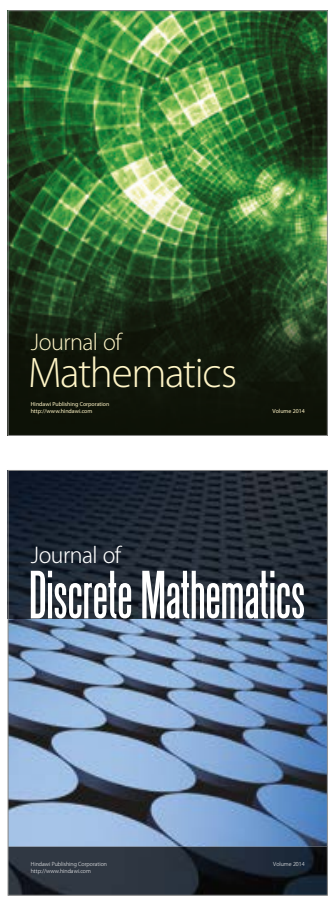

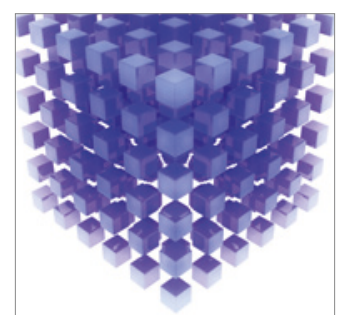

Mathematical Problems in Engineering
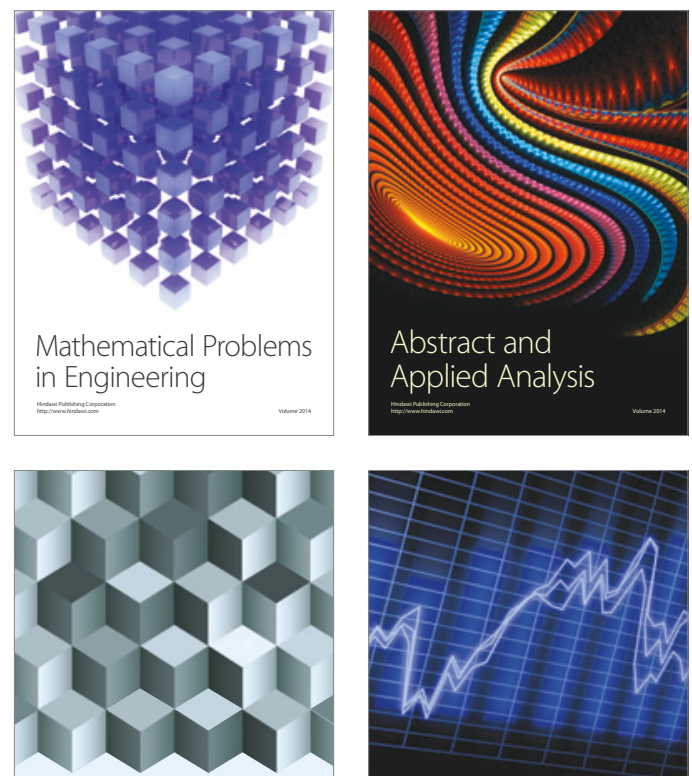

Journal of

Function Spaces

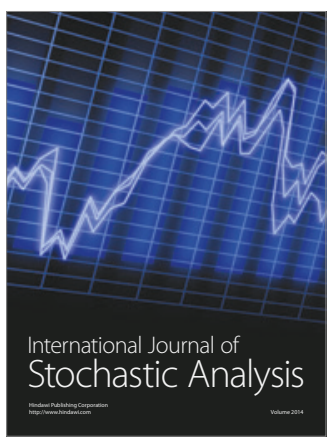

Probability and Statistics
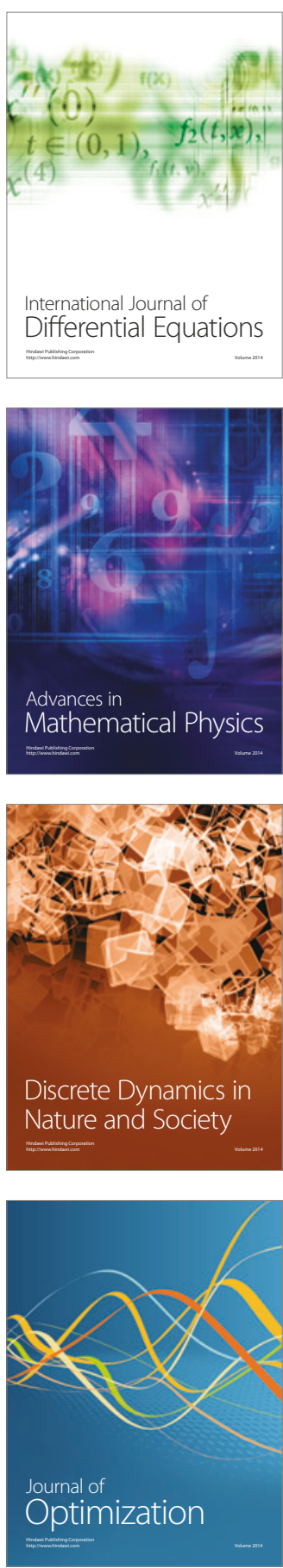